\title{
Identifikasi Meloidogyne Penyebab Penyakit Umbi Bercabang pada Wortel di Dataran Tinggi Dieng
}

\author{
Species Identification of Meloidogyne, the Primary Cause of \\ Branched Tuber Disease on Carrot in Dieng Plateu
}

\author{
Muhamad Taher, Supramana*, Gede Suastika \\ Institut Pertanian Bogor, Bogor 16680
}

\begin{abstract}
ABSTRAK
Penyakit umbi bercabang merupakan permasalahan baru dalam budi daya tanaman wortel di Indonesia. Penyakit ini dapat menurunkan kuantitas dan kualitas umbi sehingga menimbulkan kerugian yang besar bagi petani. Penyebab primer penyakit umbi bercabang wortel di daerah Jawa Barat ialah Meloidogyne spp. Penyakit yang sama ditemui di wilayah Dataran Tinggi Dieng, Jawa Tengah. Penelitian dilakukan dengan mengambil sampel di tiga lokasi di wilayah Dataran Tinggi Dieng dengan ketinggian tempat yang berbeda. Identifikasi spesies nematoda dilakukan dengan pengamatan pola perineal 150 contoh nematoda betina. Nematoda yang diperoleh ada empat spesies Meloidogyne, yaitu M. arenaria, M. hapla, M. incognita, dan M. javanica. Keempatnya ditemukan berasosiasi dengan penyakit umbi bercabang di tiga lokasi pengamatan. $M$. incognita merupakan spesies yang dominan dengan prevalensi dari $50 \%$ sampai $58 \%$.
\end{abstract}

Kata kunci: identifikasi, Meloidogyne, penyakit umbi bercabang, wortel

\begin{abstract}
Branched tuber disease is a new problem on carrot cultivation in Indonesia. The disease may reduce the quantity and quality of the tubers and causing significant yield losses. Meloidogyne spp. has been identified as the primary cause of branched or forked disease of carrot in West Java. Similar disease was observed in carrot field in Dieng Plateau, Central Java. The study was conducted at three locations in the Dieng Plateau having different elevation. Nematode species identification was done by observing the perinneal pattern of 150 samples of female nematode and obtained four Meloidogyne species, namely M. arenaria, M. hapla, M. incognita, and M. javanica. All four species were found associated with branched tuber disease in three locations with M. incognita as a dominant species having prevalence levels of $50 \%$ to $58 \%$.
\end{abstract}

Key words: branched tuber disease, carrots, Meloidogyne, species identification

\section{PENDAHULUAN}

Wortel (Daucus carota) merupakan tanaman yang berasal dari wilayah beriklim sedang, yakni Asia Timur dan Asia Tengah. Di Indonesia budi daya wortel pada mulanya hanya terkonsentrasi di daerah Lembang dan Cipanas, Jawa Barat dan kemudian menyebar

\footnotetext{
*Alamat penulis korespondensi: Departemen Proteksi Tanaman, Fakultas Pertanian, Institut Pertanian Bogor, Kampus Darmaga, Jalan Kamper, Bogor 16680

Tel: 0251- 8629364, Faks: 0251- 8629362, Surel: supramana@ipb.ac.id
} 
luas ke daerah sentra sayuran di Jawa dan luar Jawa. Luas areal panen wortel nasional mencapai 27149 ha yang tersebar di 22 provinsi (BPS 2010). Budi daya tanaman wortel di Indonesia mengalami kendala dengan adanya gangguan penyakit umbi bercabang. Penyakit umbi bercabang merupakan penyakit baru dan menjadi penyakit penting pada tanaman wortel. Kurniawan (2010) melaporkan gejala dan gangguan nematoda pada wortel berupa malformasi umbi di daerah Cipanas, Jawa Barat. Kehilangan hasil akibat penyakit ini mencapai antara 5\% dan 95\%. Gejala malformasi umbi dapat berupa umbi bercabang (forking) dan puru (galling). Selain itu terdapat pula bentuk umbi membulat dengan ukuran pendek dan membentuk akar rambut yang cukup banyak (Vrain 1982). Gejala malformasi umbi disebabkan oleh infeksi nematoda puru akar (NPA), Meloidogyne, ditemukan mulai dari dataran menengah sampai dataran tinggi. Kurniawan (2010) membuktikan penyebab utama penyakit umbi bercabang pada wortel di daerah Jawa Barat ialah NPA. Perluasan lokasi surveilan diikuti identifikasi sangat diperlukan untuk mengetahui potensi penyebaran NPA di Indonesia. Penelitian ini dilakukan untuk mengidentifikasi jenis NPA yang berasosiasi dengan penyakit umbi bercabang pada wortel di daerah Dataran Tinggi Dieng, Jawa Tengah. Penelitian ini diharapkan dapat memberikan informasi tentang spesies Meloidogyne penyebab penyakit umbi bercabang pada tanaman wortel dan dapat pula menjadi dasar untuk menentukan strategi pengendalian penyakit yang efektif dan efisien.

\section{BAHAN DAN METODE}

\section{Pengambilan Sampel Umbi}

Survei dilakukan secara acak di beberapa pertanaman wortel milik petani di daerah Desa Mlandi, Kecamatan Garung, Kabupaten Wonosobo, Jawa Tengah dan Desa Condong Campur, Kecamatan Pejawaran, Kabupaten Banjarnegara, Provinsi Jawa Tengah. Lokasi pengambilan sampel pertama bertempat di Desa Mlandi dengan ketinggian lokasi pada 1300 - 1500 m dpl, sampel kedua pada 1500
- 1700 m dpl. Sampel ketiga diambil di Desa Condong Campur, Provinsi Jawa Tengah. dengan ketinggian $>1700 \mathrm{~m} \mathrm{dpl}$.

Metode pengambilan sampel yang digunakan mengikuti pola zig-zag. Sampel yang diambil berupa sampel umbi dan perakaran wortel yang bergejala. Sampel umbi yang bergejala diusahakan dalam keadaan lembap dan disimpan dalam kantong plastik secara terpisah. Bagian atas tumbuhan biasanya lebih cepat membusuk sehingga harus ditempatkan di dalam kantong khusus bila ingin disimpan selama beberapa hari. Pendataan dilakukan untuk mendapatkan informasi awal mengenai lokasi kebun, ketinggian tempat, luas kebun, varietas wortel yang ditanam, produksi per hektar, jumlah dan tipe puru, keberadaan wortel bercabang, adanya rambut akar, teknik olah tanah, kedalaman olah tanah, jenis tanah, intensitas dan asal irigasi, penggunaan pupuk dan nematisida. Hasil pendataan dimaksudkan untuk dapat memberikan informasi tambahan tentang kondisi wilayah serta keberadaaan gejala penyakit di lahan pengamatan.

\section{Identifikasi Spesies NPA Berdasarkan pada Morfologi Sidik Pantat Nematoda Betina}

Sampel umbi dicuci untuk menghilangkan partikel tanah yang menempel terutama pada bagian perakaran. Nematoda betina yang membengkak pada jaringan puru akar dicungkil hati-hati. Bagian anterior dipotong dengan pisau khusus, kemudian bagian posterior ditekan agar kandungan di dalamnya keluar. Potongan dipindahkan ke dalam laktofenol dingin yang mengandung $0.03 \%$ cotton blue dan dibiarkan sedikitnya 24 jam. Bagian posterior disayat dan jaringan di dalam dibuang secara hati-hati. Sidik pantat (perennial pattern) kemudian dipindahkan ke gelas obyek lain dengan ditambahkan setetes laktofenol yang mengandung $0.01 \%$ cotton blue. Gelas penutup direkat dengan kuteks kemudian diamati lebih lanjut menggunakan mikroskop cahaya dengan perbesaran $400 \mathrm{x}$. Sidik pantat setiap sampel diidentifikasi mengikuti kunci (Eisenback et al. 1981). 


\section{HASIL}

\section{Kondisi Pertanaman di Lokasi Pengambilan Sampel Umbi Wortel}

Desa Mlandi terletak di wilayah pegunung an dengan tanah berjenis andosol hasil letusan gunung berapi (tanah vulkanik). Tanaman wortel merupakan komoditas yang memiliki potensi yang cukup besar di daerah ini selain kentang dengan luas panen 200 ha dan produktivitas aktual sebesar 13.18 kuintal per ha. Lahan pengambilan sampel pada lokasi 1 seluas $\pm 2000 \mathrm{~m}^{2}$ berada pada ketinggian 1300 - $1500 \mathrm{~m} \mathrm{dpl}$. Suhu pada siang hari berkisar antara $17^{\circ} \mathrm{C}$ dan $23{ }^{\circ} \mathrm{C}$ serta pada malam hari antara $13{ }^{\circ} \mathrm{C}$ dan $17{ }^{\circ} \mathrm{C}$. Lahan lokasi pertama digunakan untuk penanaman wortel secara terus-menerus. Wortel yang ditanam ialah cv. Indofood. Lahan lokasi kedua seluas $\pm 1500 \mathrm{~m}^{2}$ berada pada ketinggian 1500 - 1700 $\mathrm{m}$ dpl. Suhu pada siang hari berkisar antara $16{ }^{\circ} \mathrm{C}$ dan $22{ }^{\circ} \mathrm{C}$ dan pada malam hari antara $12{ }^{\circ} \mathrm{C}$ dan $16{ }^{\circ} \mathrm{C}$. Pada lokasi ini pola tanam wortel bergilir dengan bawang daun dan kentang, namun kadang kala dilakukan tumpang sari antara wortel dan bawang daun.

Lokasi pengambilan sampel ketiga di Desa Condong Campur berada pada ketinggian $>1700 \mathrm{~m}$ dpl. Suhu udara rata-rata di lokasi ini $19{ }^{\circ} \mathrm{C}$ dengan suhu tanah $23^{\circ} \mathrm{C}$. Penanaman wortel di lokasi ini sudah dimulai sejak 6 tahun yang lalu, namun penanaman secara intensif baru dilakukan sejak tahun 2010. Lahan penanaman wortel tidak terlalu luas karena kentang masih menjadi komoditas unggulan daerah ini. Luas lahan yang dijadikan titik pengambilan sampel $\pm 3000 \mathrm{~m}^{2}$. Wortel yang ditanam ialah cv. Indofood, beberapa petani juga menanam kultivar lokal.

\section{Gejala Penyakit}

Tanaman wortel yang terinfeksi menunjukkan gejala kerdil dan rumpun sangat jarang. Gejala pada bagian tajuk tanaman tersebut terkonsentrasi pada titik-titik tertentu di lahan pertanaman dan mengelompok. Gejala pada bagian umbi dan perakaran berhubungan dengan gejala pada tajuk tanaman. Tanaman dengan gejala kerdil bila dicabut akan terli- hat bagian umbinya bercabang dengan jumlah puru yang banyak. Gejala pada umbi yang ditemukan pada lokasi pengambilan sampel terdiri atas umbi bercabang, umbi pendek membulat, umbi pecah, dan umbi berambut.

Umbi wortel yang berukuran besar biasanya memiliki percabangan berukuran lebih kecil, pendek, dan banyak. Umbi yang berukuran kecil dan pendek, biasanya memiliki percabangan tidak lebih dari dua dan berukuran simetris (Gambar 1a). Gejala umbi pecah ditandai oleh umbi yang mengalami keadaan pecah seperti terbelah setengah bagian hingga terlihat bagian stelenya. Pada bagian permukaan biasanya terdapat kumpulan rambut akar yang berpuru bulat kecil (Gambar 1b). Umbi pendek membulat mengalami pertumbuhan abnormal dengan bentuk umbi bulat atau pendek dengan panjang sekitar 2-5 $\mathrm{cm}$. Bagian umbi yang membulat kadang-kadang dipenuhi rambut akar yang banyak dengan puru yang bulat kecil di sepanjang rambut akar (Gambar 1c). Umbi berambut sering kali muncul pada dua pertiga bagian atas umbi dengan jumlah yang cukup banyak dan juga pada bagian ujung umbi yang bentuknya membulat. Pada sepanjang umbi berambut terdapat puru yang banyak dengan bentuk bulat kecil dan berwarna putih krem (Gambar 1d).

Berdasarkan pada gejala puru pada umbi yang terserang NPA dapat dibedakan 5 tipe puru, yaitu puru bulat pada umbi berambut, puru bulat berukuran besar $( \pm 0.5 \mathrm{~cm})$, puru memanjang, puru seperti kudis, dan puru seperti akar gada. Puru bulat pada umbi berambut terbentuk di sepanjang rambut yang tumbuh di permukaan umbi wortel. Rambut terlihat jarang sampai banyak sehingga terlihat jelas berbeda dengan umbi wortel normal. Puru yang terdapat pada tipe ini berbentuk bulat kecil sempurna dengan warna putih krem (Gambar 2a). Tipe puru bulat berukuran besar banyak terdapat pada umbi wortel yang membulat dan pada percabangan umbi dan akar lateral. Puru berukuran lebih besar $(>5 \mathrm{~cm})$ berwarna sama dengan umbi wortel, umumnya permukaannya licin dan tidak ada pertumbuhan akar rambut dari puru (Gam- 
bar 2b). Puru memanjang berbentuk panjang mengikuti panjang akar. Terbentuknya puru ini diduga akibat infeksi yang tinggi sehingga menyebabkan jumlah puru yang banyak dan kemudian saling bergabung membentuk puru yang lebih besar dan memanjang (Gambar 2c). Puru seperti kudis ditandai dengan bagian akar yang terlihat seperti kudis, seperti pada bagian akar lateral yang membentuk bulatan mirip kudis (Gambar 2d). Tipe puru yang berbentuk akar gada menyerupai gejala akar gada yang biasanya terdapat pada famili kubis-kubisan, hal ini sering kali menyebabkan kesulitan membedakan jika tidak memperhatikan gejala pada bagian tajuk tanaman (Gambar 2e).

\section{Identifikasi NPA Berdasarkan pada Pola Sidik Pantat}

Berdasarkan pengamatan pada ciri-ciri khusus dari pola sidik pantat yang dimiliki nematoda betina terdapat 4 spesies NPA pada semua lokasi pengambilan sampel. Keempat spesies tersebut ialah $M$. arenaria, M. hapla, M. incognita, dan M. javanica.

$M$. incognita memiliki ciri khas lengkung dorsal yang tinggi dan menyempit, sedangkan pada bagian paling luarnya sedikit melebar dan agak mendatar, tidak memiliki garis lateral dan bagian stria terlihat jelas (Gambar 3e). M. javanica dicirikan oleh dua garis lateral yang sangat jelas (Gambar 3f), M. arenaria memiliki lengkung dorsal rendah dan ramping di sekitar garis lateral. Bagian lengkung stria bercabang di dekat garis lateral dengan bagian stria atas lebih mendatar (Gambar 3g). M. hapla dicirikan oleh lengkung dorsal yang rendah dengan bagian ujung sering membentuk sayap ke bagian lateral baik pada satu ujung atau kedua ujungnya sesuai dengan kunci sidik pantat (Gambar 3d). Pada bagian atas anus terdapat duri-duri yang menonjol tepat pada ujung ekornya.

\section{Distribusi NPA Berdasarkan pada Keting- gian Tempat}

Hasil identifikasi pola sidik pantat nematoda betina dewasa menunjukkan bahwa pada semua lokasi pengamatan terdapat tempat spesies NPA yang diidentifikasi sebagai $M$. arenaria, $M$. hapla, $M$. incognita, dan $M$. javanica. Keberadaan $M$. incognita lebih tinggi dibandingkan dengan tiga spesies lainnya. Distribusi M. incognita pada ketinggian 1300 - 1500 m dpl, 1500 - 1700 m dpl, dan >1700 $\mathrm{m}$ dpl berturut-turut 50\%, 50\%, dan 58\% (Tabel 1).

\section{PEMBAHASAN}

Gejala infeksi NPA yang ditemukan di Dataran Tinggi Dieng memiliki kesamaan dengan gejala yang dilaporkan oleh Kurniawan (2010) di daerah Jawa Barat. Tanaman bergejala terkonsentrasi pada titik-titik tertentu dan tidak dijumpai pada titik lainnya. Pada lahan dengan tingkat infeksi masih rendah pola penyebaran penyakit terjadi pada beberapa titik dan mengelompok pada guludan tertentu membentuk pola penyebaran spasial. Tanaman yang terinfeksi nematoda, bagian tajuknya mengalami kekerdilan sehingga pertumbuhan tanaman pada lahan pertanaman terlihat tidak merata, bahkan pada tingkat serangan yang tinggi dapat mengakibatkan benih tanaman mati muda. Gejala ini merupakan gejala khas dari infeksi nematoda yang disebabkan oleh melambatnya pertumbuhan tanaman.

Jenis tanah andosol di Dataran Tinggi Dieng mempengaruhi penyebaran NPA. Tanah andosol umumnya subur dan bertekstur gembur sampai seperti lempung, bahkan di beberapa tempat bertekstur debu dan agak berpasir sehingga sangat ringan diolah dan pori-pori tanahnya memudahkan sirkulasi udara masuk ke dalam tanah (Bouwman dan Arts 2001). Tanah jenis ini dapat membantu pergerakan nematoda terutama stadium juvenil. Juvenil II NPA dapat bergerak secara vertikal dan horizontal sejauh $75 \mathrm{~cm}$ dalam waktu sembilan hari pada lahan yang tanahnya berpasir. Pada lahan dengan tanah mengandung lempung lebih dari $30 \%$, pergerakan NPA umumnya sangat lambat bahkan terhenti (Kurniawan 2010).

Kondisi iklim berpengaruh terhadap distribusi spesies NPA. Suhu optimum untuk pertumbuhan $M$. incognita dan $M$. arenaria 

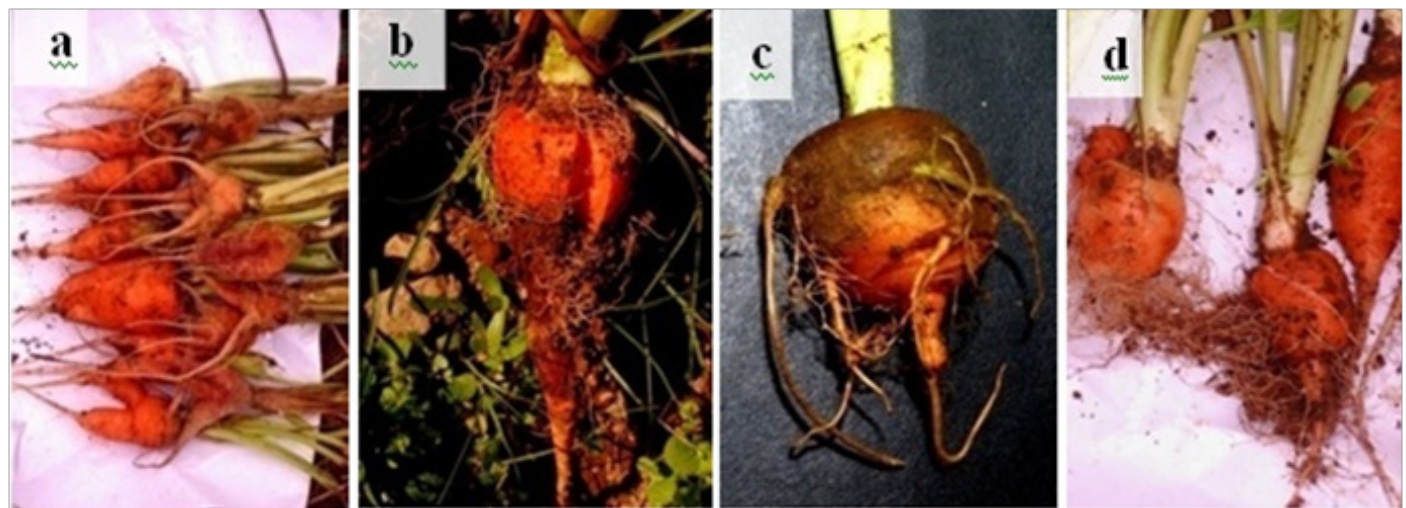

Gambar 1 Gejala umbi bercabang pada wortel dari Dataran Tinggi Dieng: a, umbi bercabang; b, umbi pecah; c, umbi pendek membulat; d, umbi berambut.
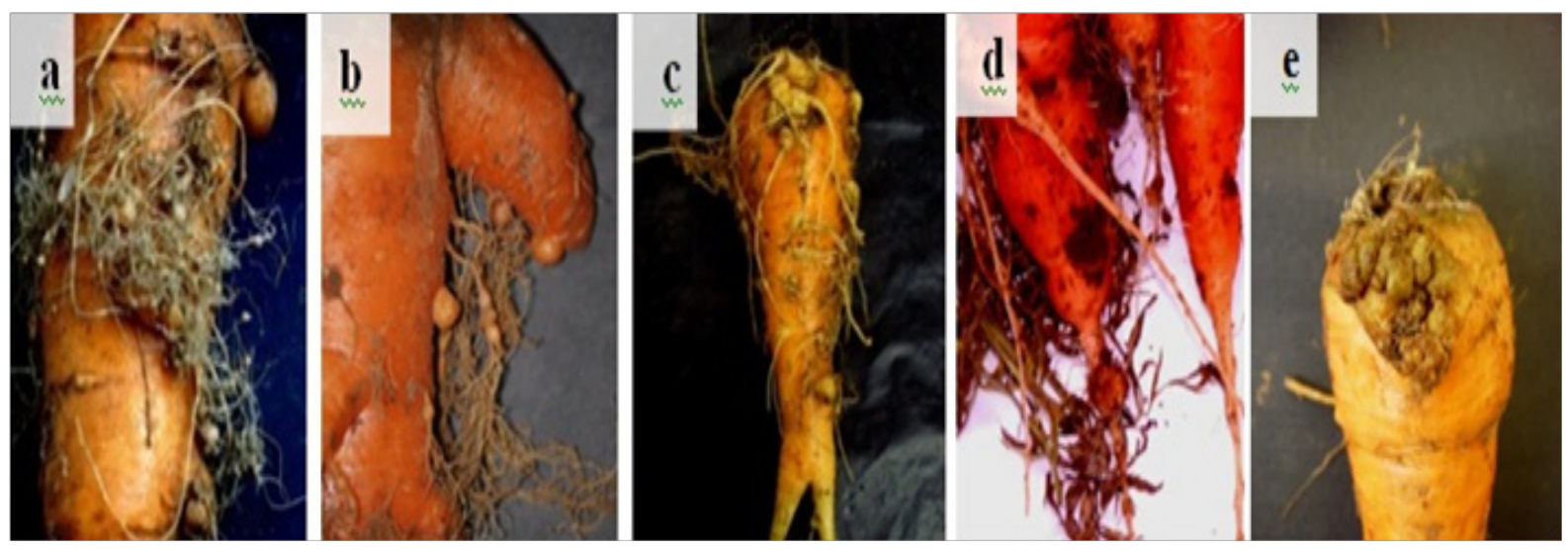

Gambar 2 Tipe puru pada perakaran wortel: a, puru bulat pada hairy root; $b$, puru bulat berukuran besar $( \pm 0.5 \mathrm{~cm})$; c, puru memanjang; d, puru seperti kudis; e, puru seperti akar gada.
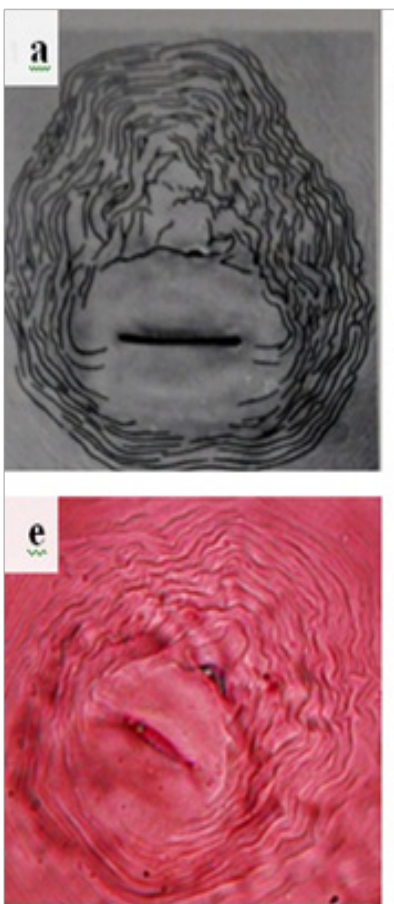
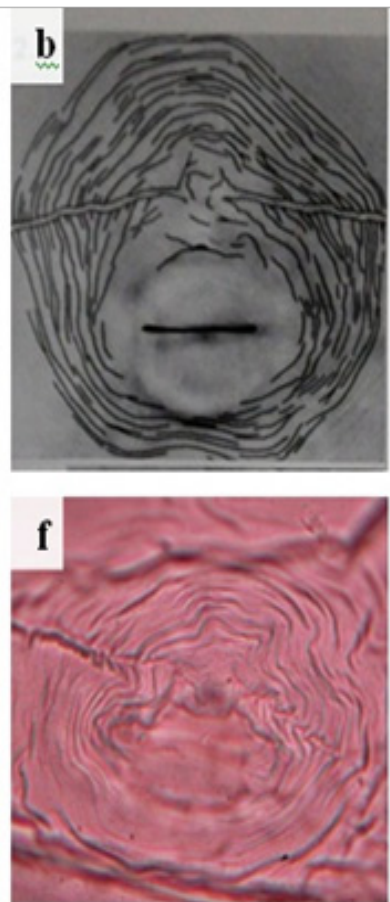
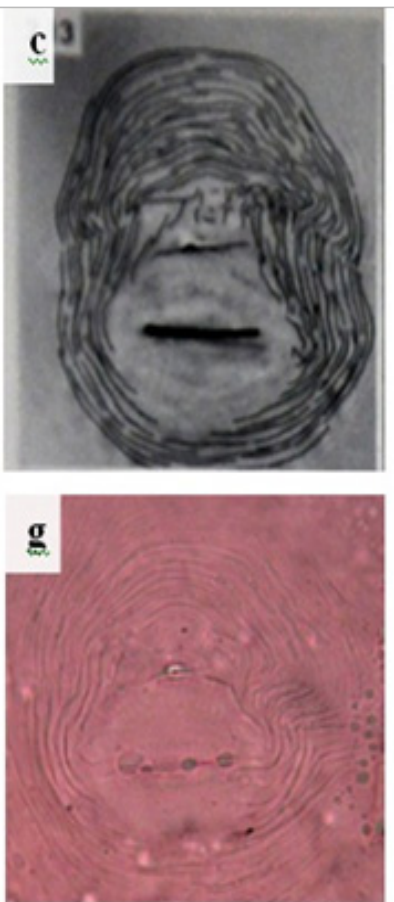

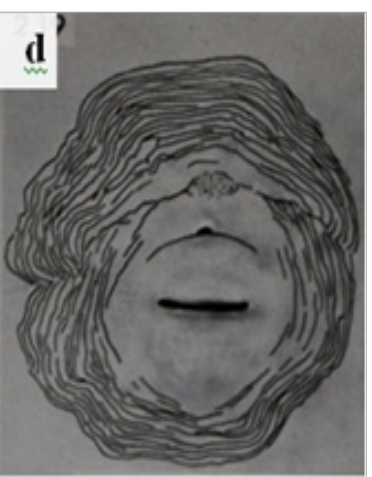

$\underline{h}$

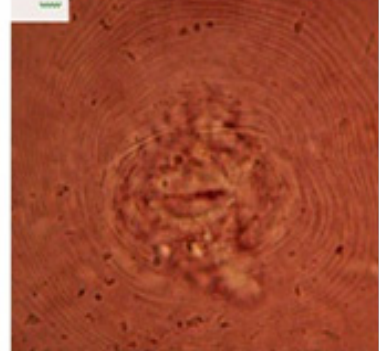

Gambar 3 Pola sidik pantat nematoda puru akar: a, M. incognita; b, M. javanica; c, M. arenaria; d, M. hapla; e-f, berdasarkan pada kunci bergambar (Eisenback 1981) masing-masing berurutan ialah M. incognita, M. javanica, M. arenaria, dan M. hapla. 
Tabel 1 Prevalensi (\%) distribusi nematoda puru akar berdasarkan pada pengambilan sampel di Dataran Tinggi Dieng pada lokasi dengan tiga tempat ketinggian

\begin{tabular}{lccr}
\hline \multicolumn{1}{c}{ Spesies } & \multicolumn{3}{c}{ Ketinggian tempat (m dpl) } \\
\cline { 2 - 4 } nematoda puru akar & $1300-1500$ & $1500-1700$ & 1700 \\
\hline Meloidogyne incognita & 50 & 50 & 6 \\
M. javanica & 26 & 14 & 32 \\
M. arenaria & 18 & 34 & 4 \\
M. hapla & 6 & 2 &
\end{tabular}

Jumlah sampel sebanyak 50 ekor betina dewasa untuk setiap lokasi

antara $15^{\circ} \mathrm{C}$ dan $25^{\circ} \mathrm{C}$; sedangkan untuk $M$. javanica antara $20^{\circ} \mathrm{C}$ dan $30{ }^{\circ} \mathrm{C}$. Prevalensi ketiga spesies NPA menunjukkan kesesuaian suhu di daerah pengamatan di Dataran Tinggi Dieng bagi pertumbuhan nematoda. Hasil identifikasi menunjukkan keberadaan $M$. hapla dengan jumlah yang kecil. Berdasarkan SK Menteri Pertanian No. 38 tahun 2008 spesies ini merupakan patogen yang masuk dalam daftar karantina yang digolongkan sebagai organisme pengganggu tanaman karantina kelas A2, artinya spesies ini sudah ada di Indonesia dan masih sangat terbatas jumlah dan penyebarannya. Secara ekologi M. hapla hanya dapat hidup dan berkembang biakpadakisaransuhuoptimum $15^{\circ} \mathrm{Cdan} 20^{\circ} \mathrm{C}$ dengan suhu optimum untuk melakukan infeksi $5{ }^{\circ} \mathrm{C}$ (Taylor et al.1982).

Pola sidik pantat merupakan salah satu teknik identifikasi nematoda yang diperkenalkan oleh Eisenback et al. (1981). Teknik identifikasi ini telah umum digunakan untuk melakukan identifikasi spesies Meloidogyne walaupun belakangan ini pendekatan biologi molekul diyakini lebih cepat dan lebih akurat untuk digunakan sebagai teknik identifikasi nematoda (Esbenshade dan Tirantaphyllou 1990). Keberhasilan mengidentifikasi empat spesies Meloidogyne dari wortel bergejala umbi bercabang perlu dilanjutkan dengan postulat Koch untuk mengetahui peran masingmasing spesies menimbulkan penyakit.

\section{DAFTAR PUSTAKA}

[BPS] Badan Pusat Statistika Republik Indonesia. 2010. Produksi sayuran Indonesia. Jakarta. http://www.bps.go.id/sector/agri/ horti/index.html. [diakses 20 Okt 2011].

Bouwman LA, Arts WBM. 2001. Effects of soil compaction on the relationship between nematodes, grass production and soil physical properties. Appl Soil Ecol. 14:213-222. DOI: http://dx.doi. org/10.1016/S0929-1393(00)00055-X.

Eisenback JD, Hirschman H, JN. Sasser, AC. Triantaphyllou. 1981. A Guide to the Four Most Common Species of Root-Knot Nematodes (Meloidogyne spp.), with a Pictorial Key. Washington DC (US): North Carolina State University Graphics.

Esbenshade PR, Triantaphyllou AC. 1990. Isozyme phenotypes for the identification of Meloidogyne species. J Nematol. 22:1015.

Kurniawan W. 2010. Identifikasi penyakit umbi bercabang pada wortel, Daucus carota (L.) di Indonesia [tesis]. Bogor (ID): Institut Pertanian Bogor.

Taylor AL, Sasser JN, Nelson LA. 1982. Relationship of Climate and Soil Characteristics to Geographical Distribution of Meloidogyne species in Agricultural Soils. Washington DC (US): North Carolina State University Graphics.

Vrain TC. 1982. Relationship between Meloidogyne hapla density and damage to carrots in organic soil. J Nematol. 14:50-57. 